ERRATA

\title{
Erratum to: Process Solutions for Recovery of Dimethyl Ether Produced Through One-Step Synthesis and Their Assessment
}

\author{
M. I. Afokin ${ }^{a, *}$ and M. V. Magomedova ${ }^{a}$ \\ ${ }^{a}$ Topchiev Institute of Petrochemical Synthesis, Russian Academy of Sciences, Moscow, 119991 Russia \\ *e-mail: m_afokin@ips.ac.ru
}

Received March 22, 2021; revised March 29, 2021; accepted March 29, 2021

DOI: $10.1134 / \mathrm{S} 0965544121050170$

The references [5-8] and [26, 27] should read as

5. https://matthey.com/en/products-and-services/chemical-processes/licensed-processes/dimethyl-ether-process

6. https://www.topsoe.com/ru/tehnologii/dimetilovyy-efir

7. http://japan-dme.or.jp/english/dme/production.html

8. https://www.mitsubishicorp.com/jp/en/pr/archive/2021/html/0000046481.html

26. https://www.engineering-airliquide.com/ru/rectisoltm-ochistka-sintez-gaza

27. https://www.clariant.com/ru-RU/Business-Units/Industrial-and-Consumer-Specialties/Gas-Treatment

The original article can be found online at https://doi.org/10.1134/S0965544121020109 